\title{
8
}
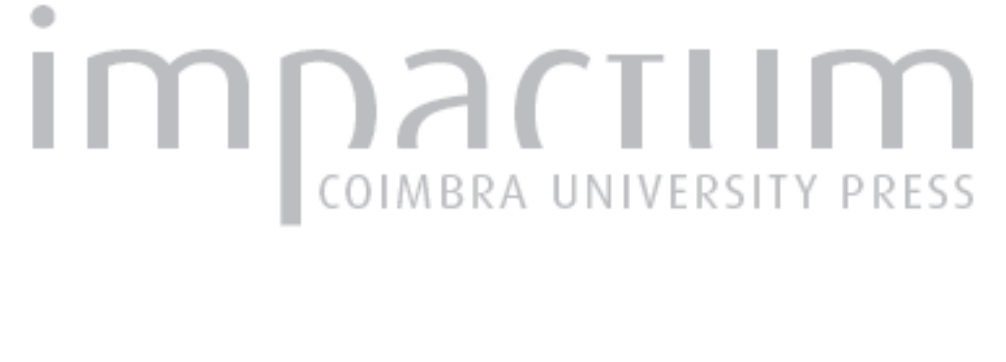

¿Ha superado la noción de persona que postula la fenomenología realista a la noción
clásica, boeciana, de persona? Autor(es): $\quad$ Casanova, Carlos A. Martins de Publicado por: $\begin{aligned} & \text { Universidade Católica de Petrópolis; Instituto Brasileiro de Informação } \\ & \text { em Ciência e Tecnologia }\end{aligned}$

URL

persistente:

URl:http://hdl.handle.net/10316.2/32943

DOI:

DOI:http://dx.doi.org/10.14195/1984-6754_5-2_2

Accessed : $\quad$ 26-Apr-2023 10:43:48

A navegação consulta e descarregamento dos títulos inseridos nas Bibliotecas Digitais UC Digitalis, UC Pombalina e UC Impactum, pressupõem a aceitação plena e sem reservas dos Termos e Condições de Uso destas Bibliotecas Digitais, disponíveis em https://digitalis.uc.pt/pt-pt/termos.

Conforme exposto nos referidos Termos e Condições de Uso, o descarregamento de títulos de acesso restrito requer uma licença válida de autorização devendo o utilizador aceder ao(s) documento(s) a partir de um endereço de IP da instituição detentora da supramencionada licença.

Ao utilizador é apenas permitido o descarregamento para uso pessoal, pelo que o emprego do(s) título(s) descarregado(s) para outro fim, designadamente comercial, carece de autorização do respetivo autor ou editor da obra.

Na medida em que todas as obras da UC Digitalis se encontram protegidas pelo Código do Direito de Autor e Direitos Conexos e demais legislação aplicável, toda a cópia, parcial ou total, deste documento, nos casos em que é legalmente admitida, deverá conter ou fazer-se acompanhar por este aviso.

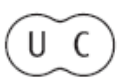



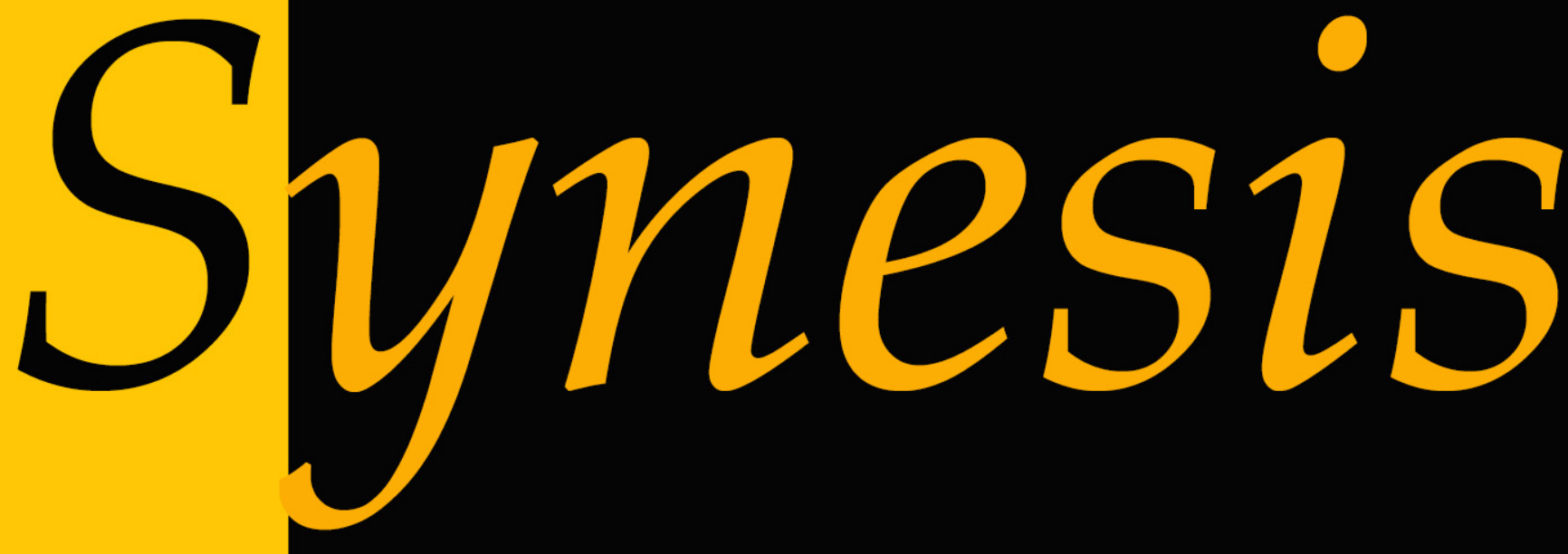

Revista do Centro de Teologia e Humanidades ISSN 1984-6754

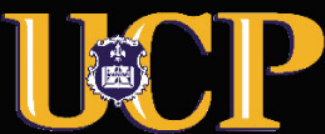




\title{
¿HA SUPERADO LA NOCIÓN DE PERSONA QUE POSTULA LA FENOMENOLOGÍA REALISTA A LA NOCIÓN CLÁSICA, BOECIANA, DE PERSONA?
}

\section{HAVE OVERCOME THE NOTION OF THE REALIST PERSON THAT PROPOSE THE CLASSIC, BOETHIAN, PHENOMENOLOGY CONCEPT OF PERSON?*}

\author{
CARLOS A. CASANOVA** \\ UNIVERSIDAD SANTO TOMÁS, CHILE \\ UNIVERSIDAD BERNARDO O'HIGGINS, CHILE
}

Resumen: Este artículo presenta primero las objeciones que John Crosby y Josef Seifert han opuesto a la noción boeciana de persona. Responde después a dichas objeciones mediante (a) una crítica a la metafísica que esas objeciones presuponen, (b) un mostrar cómo se puede atender a las principales preocupaciones de los fenomenólogos sin abandonar la noción boeciana, (c) un señalar algunos problemas teológicos que podría suscitar la metafísica fenomenológica y que, sin duda, esos dos autores desearían evitar.

Palabras clave: persona; definición boeciana de persona; persona humana, angélica, divina; relación naturaleza-persona.

Abstract: This paper expounds the objections which John Crosby and Josef Seifert have raised against the boetian notion of "person." It replies, afterwards, through (a) a critique of the metaphysics which such objections presuppose, (b) showing how the phenomenologists' main theoretical concerns can be met without abandoning the Boethian notion, and (c) pointing out some of the theological problems which the phenomenological metaphysics could raise and which the two authors studied here would like to avoid.

Keywords: person; boethian definition of person; human, angelic and divine person; Relationship nature-person.

\footnotetext{
* Artículo recibido el 21/11/2013 y aprobado para su publicación por el Consejo Editorial de 16/12/2013.

** E-mail: carlosacasanovag@gmail.com.
} 


\section{Introducción}

Me dispongo en las páginas que siguen a someter a crítica un aspecto importante de la obra de John Crosby y Josef Seifert. Debo ante todo dejar claro que respeto esa obra, en especial porque constituye un esforzado y serio intento de defender aspectos centrales de la metafísica clásica en el contexto de la tradición fenomenológica. Ambos defienden la noción de substancia y la formulación clásica de la noción de persona ${ }^{1}$, ambos sostienen que el embrión es persona desde el mismo momento de la concepción y ambos hacen esfuerzos enormes por evitar el dualismo. Por otra parte, ambos intentan incorporar aspectos de la así llamada "filosofía moderna", que tienen por verdaderos, al bagaje de la philosophia perennis. Todo esto me parece laudable.

Deseo añadir una consideración adicional. Es ya tradición que los filósofos cristianos se dividan en bandos metafísicos, sobre todo el predominantemente agustinista y el predominantemente tomista. Las razones por las que una persona particular adhiere a uno de estos bandos en lugar del otro son muchas veces no teoréticas, sino biográficas o atinentes al genio particular de cada uno. Considero que esta diversidad de perspectivas enriquece el escenario filosófico. -Pero esto no debe inhibirnos de intentar persuadir a quienes militan en el otro bando de la mayor razonabilidad de la propia posición. Eso es lo que intento hacer aquí.

Entre los fenomenólogos realistas se ha establecido la opinión de que la definición clásica de persona, boeciana y tomista, es errada o, al menos, insuficiente. Según ellos, (a) la fórmula "individua substantia rationalis naturae" es insatisfactoria porque no destaca que la persona es "incomunicable". De esta manera, se le escapa una de las fuentes más importantes de la dignidad de que está investida toda persona humana, la fuente por la que cada una es insustituible: no puede ser reemplazada por ningún individuo que posea en un grado mayor todos los valores comunes presentes en ella, tales como inteligencia, belleza, gracia, etc. ${ }^{2}$. Incluso la haecceitas escotista estaría más cerca de apuntar en la dirección correcta que la definición de Boecio, aceptada por santo Tomás. Por otra parte, la persona humana, en

\footnotetext{
${ }^{1}$ En un libro del profesor Crosby se encuentra incluso la siguiente afirmación: "tenemos ahora un título para ir y abrazar la definición boeciana [de persona]; ninguna sensibilidad personalista, ninguna preocupación por el misterio de la subjetividad personal tiene derecho alguno a impedírnoslo". The Selfhood of the Human Person. The Catholic University of [the United States of North-]America Press. Washington, 1996, p. 140.

${ }^{2}$ Crosby desarrolla este argumento con bastante agudeza en el capítulo 1 ("A Neglected Source of the Dignity of Persons") de sus Personalist Papers. The Catholic University of America Press. Washington, 2004, pp. 3-32. Lo hace en respuesta a un argumento utilitarista de Peter Singer en favor del infanticidio.
} 
particular, es individua no a causa de la materia, sino a causa de su misma esencia, que reside en el alma. Además, la persona angélica no debe concebirse al modo aristotélico y boeciano como una forma separada, porque entonces sería algo abstracto y carecería de verdadera individualidad ${ }^{3}$. El hilemorfismo, entonces, debe rechazarse porque sostendría que "una forma general se une a la materia individuante para formar una substancia concreta"4, y es inadecuado para dar cuenta de los elementos metafísicos constitutivos de las personas angélicas y humanas. Crosby desea salvar la unidad de cuerpo y alma en la persona humana ${ }^{5} \mathrm{y}$ sostener que el embrión es persona ${ }^{6}$, pero por una vía no hilemórfica. (b) Con la definición boeciana de persona, por otra parte, se incurre en una suerte de "fisicismo" (b.1) por identificar el sentido en que la persona es substancia con el sentido en que las substancias sensibles lo son. La persona, en realidad, no es substancia en el mismo sentido que las cosas no personales, pues su individualidad tiene más que ver con la auto-posesión de sí por la conciencia que con el ser en sî́; (b.2) y por describir a la persona centrándose en su "naturaleza" o en algo común, aunque sea la racionalidad". La persona, según los fenomenólogos realistas, sería más un "quién” que un "qué". Muy particularmente, la persona humana no podría definirse como "animal racional”, porque esa definición alude sólo a lo que es comunicable, mientras que cada persona, en realidad, posee su propio e incomunicable contenido esencial. Santo Tomás señaló algo semejante en relación con los ángeles, cuando dijo que cada uno agota su especie, y en este punto superó a Aristóteles ${ }^{9}$. En esta línea, (b.3) la noción clásica no destaca suficientemente la diferencia que existe entre predicar "persona" de algo y predicar "silla", por ejemplo. Es decir, parece "cosificar" a la persona. En este contexto,

${ }^{3}$ Cfr. Josef Seifert. Essere e Persona. Vita e Pensiero. Milán, 1989, pp. 336-339, 343 y 366-368.

${ }^{4}$ Cfr. John Crosby, The Selfhood of the Human Person (cit.), pp 43 y 264.

${ }^{5}$ Cfr. John Croshy, The Selfhood of the Human Person (cit.), pp. 127-144 y 260-266.

${ }^{6}$ Cfr. supra nota 2.

${ }^{7}$ Cfr. Josef Seifert. Essere e Persona (cit.), pp. 343, 344-347 y 353.

${ }^{8}$ Cfr. John Crosby. The Selfhood of the Human Person (cit.), pp. 50 y 59-60. Crosby llega a atribuir la incapacidad platónica manifestada en el libro $\mathrm{V}$ de la República para percibir la preciosidad de cada ser humano y permitir el aborto y el infanticidio al hecho de haber percibido sólo los elementos esenciales de la persona, y no su incomunicabilidad. Aristóteles habría luchado por entender esta incomunicabilidad, pero habría fallado a causa de los restos de platonismo que había en su pensamiento (cfr. pp. 61-62). No creo que fuera éste el problema. De hecho, Platón cambia su opinión en el libro VIII de las Leyes (838-841) y prohíbe que se dé muerte deliberadamente al género humano, haciendo alusión al aborto y al infanticidio, precisamente.

${ }^{9}$ Cfr. John Crosby. The Selfhood of the Human Person (cit.), pp. 57-59 y 63-65. Crosby sabe que la definición de Aristóteles significa la esencia común a todos los hombres y, sin embargo, la critica. Esto debe destacarse, porque contribuye a subrayar la impresión de que Crosby desea negar la esencia común en las personas, impresión que podría no ser del todo justa. Puede encontrarse una crítica sensata a puntos de vista semejantes a los de Crosby en el libro de Antonio Millán Puelles, La inmortalidad del alma bumana. Rialp, Madrid, 2008, pp. 28 y 80-81. Josef Seifert sostiene una posición semejante a la de Crosby en Essere e Persona (cit.), pp. 337-339: la individualidad de la persona, también de la persona humana, vendría de que su propia esencia y ser sería individualizado, nunca vendría de la materia. La persona, también la persona humana, por ser espiritual, se hallaría más allá de todo género material. 
Crosby señala que a causa de su errada concepción de la persona, que traslada al hombre lo que pertenece a las cosas sensibles, Aristóteles no llegó a concebir la insustituibilidad de la persona humana, prueba de lo cual sería que permitió el aborto y el infanticidio y declaró que el esclavo debe gobernarse en orden al bien de su señor ${ }^{10}$.

Queremos delinear con la mayor brevedad posible la respuesta que, a nuestro parecer, daría santo Tomás si pudiera escuchar estas críticas. (I) Mostraría, en efecto, en primer lugar, que la concepción metafísica desde la que se critica la definición de Boecio es de corte platónico e ignora las dificultades que Platón no pudo resolver y a las que atendió Aristóteles con sus nociones de hypokeímenon y próte ousía. (II) Después señalaría cómo se incorporan en la concepción metafísica clásica las preocupaciones legítimas de los fenomenólogos. (III) Finalmente mostraría los problemas teológicos que en este punto plantea la concepción metafísica fenomenológica.

\section{Dificultades insolubles para el platonismo. La pequeña observación de Antístenes}

La fenomenología realista concibe a la persona y a la cosa concreta como un "sujeto" con una esencia concreta en el que se dan diversas "esencias necesarias" o valores, además del acto de ser ${ }^{11}$. Este darse de las esencias en lo concreto se formula de diversos modos. El profesor Seifert piensa que hay esencias concretas en la cosa, y paradigmas necesarios y trascendentes en la Mente de Dios, participados por la cosa concreta existente, en una síntesis de sujeto, esencias (individuales, generales y trascendentes) y existencia. De esta manera parece escapar a algunas de las aporías planteadas por Platón en el Parménides y por Aristóteles en la Metafisica. Su fina formulación, sin embargo, no logra superar el problema álgido que llevó a Aristóteles a abandonar la teoría de las ideas.

En el Sofista, Platón intenta lidiar con la objeción de un anciano (Antístenes) que se entretiene con razonamientos juveniles y que cree que es el colmo de la sabiduría afirmar que "hombre" sólo se puede predicar de la "humanidad" presente en el sujeto concreto, pero no

10 Crosby atribuye la objeción de que es “demasiado 'cosmológica", dirigida contra la noción clásica de substancia, nada menos que a Karol Wojtyla. Cfr. The Selfhood of the Human Person (cit.), p. 126.

11 Cfr. Essere e Persona (cit.), pp. 250-260. Debo decir que la posición del profesor Crosby es más cauta en este punto, pues en las pp. 43-44 de The Selfhood of the Human Person no sostiene explícitamente la pluralidad de esencias y, aunque sostiene que existe una conexión de la esencia de la cosa concreta con el arquetipo divino, la concibe de una manera que excluye toda pluralidad esencial. Sin embargo, si consideramos su crítica a la definición aristotélica de "hombre" podemos atisbar que también Crosby se debería enfrentar con las dificultades que vemos en la posición de Seifert, pues ambos postulan que cada persona tiene en sí esencias comunicables ("racionalidad", por ejemplo), pero también una esencia incomunicable... 
del sujeto mismo. Porque el sujeto es también "blanco" y la "blancura" no es la "humanidad". Si se dijera del sujeto el predicado "hombre", entonces, la misma cosa sería una vez "hombre" y mil veces "no hombre"12. A pesar de la mordacidad que usa, no logra en realidad Platón responder cabalmente. Sí muestra que algunos de los predicados considerados universalmente se pueden mezclar y otros no, y que la dialéctica se ocupa del arte de mezclar bien las ideas. También muestra que algunas palabras se pueden mezclar y otras no, y que la gramática es el arte que se ocupa de mezclar bien las palabras. Pero cuando llega a la cosa concreta, escamotea el problema insensiblemente. Nos dice, en efecto, que "Teeteto vuela" es un ejemplo de proposición falsa, con mala mezcla; y que "Teeteto está sentado" es un ejemplo de proposición verdadera ${ }^{13}$, con buena mezcla. Pero hay que notar que ambas proposiciones vinculan un predicado universal directamente al particular, de tal manera que basta verificar si ese predicado se da en el sujeto para determinar si la proposición es verdadera o falsa. Si se hubieran dado ejemplos de predicaciones más sofisticadas y referidas a un sujeto concreto, no habría sido tan fácil aparentar que se estaba resolviendo la aporía planteada por el anciano de marras. ¿Podría decirse, por ejemplo, “este hombre está sentado”? Este problema quedó insoluto porque Platón concebía al sujeto concreto como un "lugar" donde se hacían presentes las ideas o esencias, por medio de la participación, en pie de igualdad. Entonces, si "hombre" no es "estar sentado", ¿por qué puedo decir de "hombre" que "está sentado"? Parecería que sólo puedo decir del sujeto que es hombre y que está sentado, pero no del hombre que esté sentado. Si damos un paso más, llegamos a la propuesta de Antístenes nuevamente: si "el hombre" no es "estar sentado", entonces parece que no puedo decir del sujeto que sea hombre y que esté sentado, porque en ese caso lo mismo que es hombre sería lo que es estar sentado.

Sólo Aristóteles pudo responder cabalmente a este problema. ¿Cómo? El Estagirita observó que no todos los predicamentos metafísicos tienen la misma relación con el sujeto concreto. Los predicamentos substanciales se identifican con la esencia del sujeto, de tal manera que cuando digo "Teeteto es hombre", estoy en verdad respondiendo a la pregunta “¿qué es Teeteto?”. Pero si se me objeta, como hacía Antístenes, que Teeteto también es "blanco" o también "está sentado", le debo responder: no se me ha preguntado cómo es Teeteto, sino qué es Teeteto. De esta manera se ve que el bypokeimenon no es una simple chóra, un lugar donde se hagan presentes las ideas, sino que es algo determinado. Es tóde ti. No es

${ }^{12}$ Cfr. Sofista, 251 a-c.

${ }^{13}$ Cfr. Sofista, 251c-263d. 
sólo "esto", sino que es "algo"".

Los fenomenólogos realistas, con su insistencia en la haecceitas, han abrazado una concepción del sujeto concreto que, como la chóra platónica, estaría expuesta a la crítica de Antístenes. Es cierto que el sujeto concreto no es comunicable. Tampoco lo es la próte ousía, la substancia primera. Esto es verdad no sólo de la persona, sino también de cualquier ente concreto, substancial o accidental. Pero, la substancia primera no es una pura "estoidad", es también algo. También la sustancia primera personal.

\section{Las legítimas preocupaciones de la fenomenología realista asumidas por la metafísica clásica}

Hemos visto que la metafísica aristotélica, presupuesta por Boecio y santo Tomás en este punto, explica muy bien la incomunicabilidad de la persona ${ }^{15}$, que es una de las preocupaciones de los fenomenólogos. Avancemos un poco más, para ver cómo incorpora sus otras preocupaciones legítimas.

En primer lugar, está claro que cuando se habla de "naturaleza racional" no se está tomando "naturaleza" en el mismo sentido que objeto de la física. Esa palabra, "naturaleza", se introdujo originalmente para significar la generación de los seres vivos, que se da a partir de un principio intrínseco. De aquí se extendió para significar el principio intrínseco de todo movimiento, que es como se toma en la Física. Pero ese principio intrínseco del movimiento puede ser tanto formal como material, y como por la forma se completa la esencia de cada cosa, vino a darse el nombre de "naturaleza" a toda esencia. Y éste es el sentido que se da a "naturaleza" en la definición de Boecio, para nada limitado a los entes físicos ni a la dimensión física de los entes físicos ${ }^{16}$.

En segundo lugar, el "ser individuo" es común a los accidentes y a las substancias concretas, pero se da sobre todo en las substancias, pues los accidentes son modos de ser de éstas. Además, entre las substancias, son especialmente las "racionales" las que tienen individualidad en el pleno sentido de la palabra, porque ellas son dueñas de sus actos y no son dirigidas por otro, a diferencia de las demás substancias. Sus acciones, que son concretas, son suyas de un modo especial. Así que son individuales de un modo más perfecto. Por esto se

\footnotetext{
${ }^{14}$ Cfr. Metafísica Gamma 4, 1006b11-1007b18.

${ }^{15}$ Cfr., en este sentido, Summa Theologiae I q. 29 a. 3, ad 4m.

${ }^{16}$ Cfr. S. Th. I q. 29 , a. 1 , ad $4 \mathrm{~m}$.
} 
distinguen de las otras substancias primeras (no intelectuales) con el nombre de "persona"17, porque "entraña una gran dignidad el subsistir en la naturaleza racional"18, "persona significa lo más perfecto en toda la realidad"19. Nótese que si la persona es digna e insustituible es precisamente por el tipo de ser que es, por la naturaleza o esencia en la que subsiste.

Por supuesto, cada persona humana posee una naturaleza humana concreta, no es una simple "participación" en una naturaleza común. Para cada ser humano, "ser", "ser hombre” y "ser este hombre" son lo mismo. Y, desde luego, el subsistir en esta naturaleza racional hace de cada ser humano algo precioso e insustituible. Como lo ha expresado admirablemente Richard Stith: las personas son principios del razonamiento práctico. Cuando se delibera sobre el bien común, se delibera sobre el bien de todas las personas implicadas. No puede considerarse a una persona como un mero medio para acrecentar la utilidad o el "valor" ${ }^{20}$, como querría un utilitarista del tipo de Peter Singer. De hecho, en la formulación de este punto del carácter insustituible de la persona que se encuentra en dos artículos de John Crosby, "A Neglected Source of the Dignity of Persons" ${ }^{21}$ y "Personal Individuality: Dietrich von Hildebrand in Debate with Harry Frankfurt"22, no encuentro problema, precisamente porque no se concibe

${ }_{17}$ Cfr. S. Th. I q. 29, a. 1, c. En sentido semejante, y apoyado en citas de la Summa contra Gentiles, cfr. Essere e Persona (cit.), pp. 348-350.

${ }^{18}$ Cfr. S. Th. I. q. 29 a3 ad 2m. Y añade allí mismo santo Tomás: "por eso algunos definen a la persona así, persona es la hypóstasis distinguida con la propiedad de que le corresponde la dignidad".

${ }^{19}$ S. Th. I, q. 29, a. 3, c. En sentido semejante, cfr. Josef Seifert. Essere e Persona (cit.), p. 328.

${ }^{20}$ Cfr. "Her Choice, Her Problem: How Having a Choice Can Diminish Family Solidarity," pp. 205,211 y 213. International Journal of the Jurisprudence of the Family, Volume 2 (2011), pp. 179-213. Stith rechaza aquí el calificar a la persona humana como "fin en sí mismo", y propone calificarla, en cambio, como "principio", en el sentido indicado.

${ }^{21}$ Cfr. op. cit. En esta obra Crosby incluso niega que pueda decirse de las personas humanas lo mismo que dice santo Tomás de los ángeles, que cada una tenga su propia especie (cfr. pp. 21-22). Yo estaría enteramente de acuerdo con las tesis que contiene, si no afirmara en la p. 7 que la racionalidad es siempre universal: la racionalidad ética no es universal, pues la verdad práctica tiene en consideración la proporción de las cosas al agente concreto.

22 Cfr. Ethical Personalism. Cheikh Gueye (ed.). Ontos Verlag. Heussenstamm, 2011, capítulo 2 ("Personal Individuality: Dietrich von Hildebrand in Debate with Harry Frankfurt”), pp. 19-31. Me parece que podría aceptarse la siguiente formulación: "como una emanación del ser de cada persona irrepetible hay una cierta radiación o esplendor que es el valor irrepetible de cada uno" (p. 22), siempre que no se entienda "valor" como un contenido esencial sobreañadido a la naturaleza humana particular de cada persona. Con esta aclaratoria, podría estar enteramente de acuerdo con la tesis central de este artículo, que consiste en que el amor interpersonal se puede basar en un conocimiento de una inteligibilidad individual (cfr. p. 28). No estaría de acuerdo, en cambio, con dos puntos colateralmente tocados en el artículo: que los griegos hayan negado que pueda haber conocimiento intelectivo de lo individual (cfr. p. 28) o que todo eudaimonismo implique una instrumentalización de las personas. Discutir este segundo punto nos llevaría muy lejos del hilo del presente artículo. Sobre el primer punto, solamente traeré a colación un texto: "Todas las cosas relativas a la acción se refieren a lo particular y los límites. Pues al prudente le es preciso conocer esas cosas [...]. También el intelecto se refiere a los límites en ambas direcciones puesto que de los primeros y últimos límites hay intelecto pero no razón, tanto el intelecto referido a las demostraciones, que es de los primeros límites e inmóviles, como el intelecto referido a las cosas prácticas, que se refiere a lo último y a lo posible y a la otra premisa, pues tales son los principios de la causa final [tô̂u hồ héneka], pues es a partir de lo particular como se obtiene lo universal. De estas cosas es preciso, por tanto, tener percepción, pero ésta es intelecto [noûs]". (Ética a Nicómaco VI 11, 
la concreción de la persona humana como un contenido esencial que difiera en cada uno. De hecho, en el primer artículo mencionado se dice: “[...] lo común y lo incomunicable no son dos partes diferentes de un ser humano que se encuentren fuera la una de la otra. Más bien, cada persona incomunicable modifica la naturaleza humana que comparte con otras, no simplemente ejemplificándola, sino casi tomándola como propia, de tal manera que cada una existe no como una entre muchas, sino como si fuera el único ser humano"23.

En tercer lugar, está claro que la persona no es sólo un qué, sino también y sobre todo un quién ${ }^{24}$. Es correcto, además, decir que "persona" no se predica de una cosa de la misma manera que un predicado esencial como "hombre", porque éste, a diferencia de aquél, deja de lado las condiciones individuantes ${ }^{25}$. Ahora bien, el ejemplo dado por algún fenomenólogo para distinguir la predicación esencial de la personal (la manera en que se predica "silla" es diferente a la manera como se predica "persona"), no es un ejemplo muy feliz, porque la silla no es, desde el punto de vista natural, una "cosa", sino un artefacto hecho de substancias naturales que son "cosas". "Silla" sería, pues, un todo de orden, no un todo substancial. Cuando lo predico de esta cosa que tengo aquí debajo de mí no estoy haciendo, en realidad, una predicación esencial.

En cuarto lugar, es verdad que la materia signata quantitate no es la causa permanente de la individuación humana. Si bien Aristóteles no fue explícito en el tratamiento de este tema, santo Tomás extrajo algunas consecuencias obvias de los principios aristotélicos cuando dijo que la materia signata quantitate es principio de la individuación pero sólo en cuanto a la incoación ${ }^{26}$. En efecto, una forma no podría multiplicarse en muchos individuos a menos que para existir debiera requerir de una base material. Sin embargo, una vez que existe el ente

1143a32-b6).

${ }^{23}$ P. 17. Esta formulación me parece inobjetable si se interpreta este pasaje conforme a lo dicho en el texto (la naturaleza humana se da en mí de un modo concreto), y no de una manera cuasi-platónica, como que todos "participamos" concretamente de la única naturaleza humana que se da en la Mente de Dios o en cualquier otro "lugar" (cfr. p. 18).

24 S. Th. I, q. 29 , a. 4.

${ }^{25}$ S. Th. I, q. 29, a. 3 ad 4m; y a. 4, c. En el último pasaje se dice, por cierto, que "esta carne, estos huesos y esta alma" son los principios individuantes del hombre. Santo Tomás sostiene sistemáticamente que la materia es el principio de individuación en cuanto a la incoación, pero que el alma humana es principio de individuación en cuanto a la subsistencia.

${ }^{26}$ Cfr., por ejemplo, De Ente et Essentia, capítulo 4, donde se dice: "Y por ello, en tales substancias (separadas o intelectuales) no se encuentra multitud de individuos en una especie, como se dijo, excepto en el alma humana a causa del cuerpo, al cual está unida. Y aunque su individuación dependa ocasionalmente del cuerpo en cuanto a su incoación, porque ella no adquiere su ser individuado sino en el cuerpo, del que es acto, sin embargo, no conviene que quitado el cuerpo perezca la individuación, porque, puesto que tiene un ser absoluto [es decir, desligado de la materia o incorpóreo, como ha dicho antes, en el capítulo 3], desde que adquirió un ser individuado por haber sido hecha forma de este cuerpo, aquel ser siempre permanece individuado. Por eso dice Avicena que la individuación o multiplicación de las almas depende del cuerpo en cuanto a su principio, pero no en cuanto a su fin". 
concreto, lo que lo hace ser es la forma ${ }^{27}$. Y para un ente concreto es lo mismo ser, ser uno y ser lo que es. La unidad, una vez que existe el ente concreto, depende de la forma, entonces, tanto según Aristóteles como según santo Tomás. Pero ser uno es ser indistinto de sí y distinto de otros seres. Es obvio, entonces, que la individualidad está estrechamente conectada a la unidad y que, en consecuencia, depende de la forma en lo que se refiere no a la incoación, sino a su continuidad. En el caso del ser humano, la individualidad se mantiene después de la muerte y, por ello, hay una multiplicidad de almas separadas, antes de la resurrección ${ }^{28}$. Debe saberse, sin embargo, que si es posible esta multiplicidad de cuasi-substancias separadas en una misma especie es porque ellas comenzaron a ser en el cuerpo y porque tienen poder de actualizar el cuerpo de maneras diferentes ${ }^{29}$. Esto es otro modo de decir que el hombre no es un ángel encarnado.

Quizá el profesor Crosby no haya conocido otra interpretación del hylemorfismo que la que hemos presentado en la introducción. Pero la verdad es que ni Aristóteles ni santo Tomás sostienen que una "forma general” entre en composición con nada. En el concepto se halla la esencia general abstraída de la materia concreta, pero esa "esencia general" no es un principio ontológico de la cosa. Desde luego, la forma de cada cosa es concreta. Pero constituye una estructura inteligible que, al ser comunicada por un agente concreto, asume en sí una cierta materialidad (concreta, desde luego), que puede ser concebida de modo $\operatorname{abstracto~}^{30}$. En opinión de Antonio Millán Puelles, no hay mejor explicación al problema de la relación entre nuestros conceptos generales y las cosas concretas ${ }^{31}$.

Es una pena que Crosby haya rechazado el hylemorfismo, porque sólo esta doctrina podría darle las herramientas adecuadas para superar el dualismo ${ }^{32}$. De hecho, a pesar de todos

\footnotetext{
27 Josef Seifert observa agudamente que no puede ser que la mayor actualidad del ente concreto venga de la materia, que daría a la forma el ser real en acto (cfr. Essere e Persona [cit.], p. 367). Aristóteles no dijo eso, sino, más bien, que el ser en acto dependía de la copulación actual de materia y forma. David Twetten, más agudamente, observó que el ser concreto es más actual que el universal en un sentido. Pero esta mayor actualidad no puede proceder de la materia, que es potencial, ni de la forma, que separada de la materia [en el intelecto] es universal. Entonces debe proceder la mayor actualidad de un acto que esté más allá de la esencia (compuesta de materia y forma). Ralph McInerny concluye de aquí que la distinción real entre esencia y acto de ser fue conocida por Aristóteles (Cfr. Praeambula Fidei. Thomism and the God of Philosophers. The Catholic University [of the United States] of America Press. Washington, 2006, pp. 303-304. En esto último me encuentro en desacuerdo con McInerny).

${ }^{28}$ Cfr. Quaestio Disputata de Anima, a. 3, c.

${ }^{29}$ Cfr. Quaestio Disputata de Anima, a. 3, ad 15m, 19m et $20 \mathrm{~m}$.

${ }^{30}$ Cfr., en este sentido, Carlos A. Casanova, "Ideas, esencias, conceptos y arte divino. ¿Se puede compatibilizar un aspecto central de la teoría platónica de las ideas con una metafísica de corte aristotélico?”, pp. 132-135, Revista de Filosofía 37/2 (2012), pp. 131-150.

${ }^{31}$ Millán Puelles, Antonio. La inmortalidad del alma humana. Ediciones Rialp, S. A. Madrid, 2008, pp. 76-77.

${ }^{32}$ Cfr., por ejemplo, A. C. Crombie. Historia de la ciencia. De san Agustín a Galileo. Alianza Universidad. Madrid, 1993, Vol. II, p. 275: "Para la filosofía aristotélica no había, hablando estrictamente, ningún problema del cuerpo y
} 
sus esfuerzos, no logra hacerlo, y sigue viendo al yo o a la persona como idéntica con el alma, que "tiene un cuerpo". Por eso declara, por ejemplo, que el cerebro u otros órganos no son sino "condiciones" de todos los actos de la vida consciente, cuando, en realidad, constituyen verdadera causa material o co-sujeto de ciertos actos de la vida consciente, como las sensaciones y las pasiones ${ }^{33}$. O declara, también por ejemplo, "que yo, que ahora vivo y actúo como una persona encarnada, comencé a existir cuando mi cuerpo comenzó a existir" ${ }^{34}$. Es una pena, como digo, porque sólo mediante el hylemorfismo podría explicar adecuadamente por qué el embrión es persona humana, por qué la persona está inmersa en el tiempo, por qué se desarrolla inicialmente con el cuerpo, etc., que son todas cuestiones que él desea explicar adecuadamente, y a las que se acerca con una energía y una inteligencia poco usuales ${ }^{35}$. En ese contexto, sea dicho de paso, Crosby lanza un agudo ataque al aristotelismo, que sostenía que la vida humana no comenzaba en la concepción ${ }^{36}$. Pero pasa por alto que hoy en día ningún verdadero aristotélico sostendría esa opinión, porque con el descubrimiento del gameto femenino es obvio que el evento causal que da lugar a la nueva vida humana es la concepción. El resto de la argumentación de Crosby en esta materia es, por lo demás, aristotélico ${ }^{37}$.

En quinto lugar, Aristóteles no concibe a las substancias separadas como "formas" abstractas. Su crítica a Platón, sobre todo tal como se formula en el libro Lambda de la Metafísica (capítulos 6, 9 y 10), precisamente se centra en decir que la realidad más alta es Intelecto, no simple Inteligible, que las Ideas separadas no podrían ser activas porque no son verdaderas substancias y que Dios no podría ser tampoco “alma” (es decir, una forma viva), porque el alma no es acto puro. Josef Seifert interpreta mal a Aristóteles cuando le atribuye sostener que puesto que sólo la materia signata quantitate es principio de individuación, entonces (a) las substancias separadas deben ser formas abstractas, o (b) la materia es el bypokeimenon en el sentido más propio de la palabra. Como hemos visto, Aristóteles piensa que el predicado substancial se identifica con la esencia del bypokeimenon, y en el libro Dseta de la

la mente, porque el alma, el animus de los escolásticos, que incluía a la mente [...], era la "forma" del ser humano, y determinaba la naturaleza de la unidad psicofísica de la misma manera que la forma de un cuerpo inanimado determinaba su naturaleza. El problema surgió con la concepción mecanicista del cuerpo".

${ }^{33}$ Cfr. The Selfhood of the Human Person (cit.), p. 138-139. La expresión que usa es "condiciones causales". Se podría interpretar más benévolamente, de modo que abarque a la causalidad material en el caso de los actos no intelectivos o volitivos. Pero, en esa lectura se estaría atribuyendo a Crosby el hylemorfismo.

${ }^{34}$ The Selfhood of the Human Person (cit.), p. 143.

35 Así, por ejemplo, su respuesta al argumento basado en la posibilidad de la gemelación contra el carácter personal del embrión es acertado: se trata de un caso de posible reproducción asexuada (cfr. The Selfhood of the Human Person [cit.], p. 142).

36 Cfr. The Selfhood of the Human Person (cit.), p. 142-143.

${ }^{37}$ Piénsese, por ejemplo, en el argumento que apunta la identidad del organismo desde que es embrión hasta que es cuerpo humano desarrollado, para expresarlo en los mismos términos dualistas en que se expresa Crosby (cfr. p. 143). 
Metafisica se muestra que por eso la forma es más propiamente substancia y bypokeimenon que la materia ${ }^{38}$. Todo lo que Aristóteles quiere decir, cuando dice que la materia es principio de individuación, es que en las formas de lo sensible, entre las que una especie se da en muchos individuos, la multiplicación de una misma forma en muchos individuos se debe a su dependencia de la materia. En el caso de los ángeles, que son seres puramente "formales" (pero no formas, sino, precisamente, substancias separadas), cada esencia es única e irrepetible, agota su género y su especie, y es mucho más individua, mucho más "una”, para usar la expresión de Aristóteles, que lo sensible. Su unidad no consiste en la indivisión, sino en la simplicidad y, por eso, se identifican en ellas la cosa y la esencia ${ }^{39}$. -Sin embargo, no son "individuos de una especie", sino una especie individuada por sí. En el caso de Dios, la Esencia es Única e irrepetible pero los Sujetos que la poseen son tres, individuados, por supuesto, no por relación alguna con la materia, sino por las relaciones de procedencia. Esto, desde luego, es un misterio que no podemos comprender, pero del que podemos ver que no es contradictorio porque podemos comprender en las criaturas que hay una diferencia entre la esencia o naturaleza, por una parte, y el sujeto o la persona que posee aquélla, por otra.

En sexto lugar, no cabe la menor duda de que Aristóteles se equivocó en las concepciones morales señaladas por Crosby (aborto, infanticidio, esclavitud por el bien del amo), ni de que el viejo Platón se acercó mucho más a la verdad en lo que se refiere a ellas. Pero no es verdad que la limitación moral de Aristóteles se derive de su concepción de la substancia. De hecho, su concepción de la substancia es muy superior a la platónica, mientras la concepción moral platónica sobre los puntos señalados es superior a la aristotélica. Por otra parte, los cristianos aceptaron sin problemas la concepción aristotélica de la substancia por 1.600 años, a contar desde el siglo III, a pesar de que se les había revelado que Cristo, el Hijo de Dios, ha muerto por cada ser humano, cuya preciosidad quedó así puesta a una luz insospechada con la sola razón natural. Nada tiene que ver una cosa con la otra, entonces. No debe anteponerse la moral a la metafísica al modo kantiano, en la consideración del noúmeno.

\section{Las poderosas dificultades teológicas que han de afrontar los fenomenólogos realistas}

\footnotetext{
${ }^{38}$ Cfr. 3, 1028b33-1029a30.

39 Cfr. Metafísica Dseta 11, 1037a33-1037b7. En realidad, la metafísica tomista, que va más allá de lo que Aristóteles dijo en este punto, señala que tampoco en los ángeles se da una identidad entre la esencia y la cosa, aunque en ellos haya mucho mayor unidad que la que alcanzan los seres sensibles o los hombres.
} 
Pienso que la relevancia de este apartado del presente artículo para el debate filosófico se puede justificar si se piensa que, aunque la teología se funde en artículos de Fe, los filósofos cristianos intentan que sus conclusiones racionales no contradigan esos artículos. En el caso de los dos autores que aquí se consideran, no hay duda de que comparten esta preocupación con el autor de las presentes páginas ${ }^{40}$. En este plano pueden estudiarse dos tipos de dificultades, unas relacionadas con la Encarnación y la Redención, y otras relacionadas con la Trinidad. Veámoslas.

Es cierto que las substancias separadas agotan su especie y su género. De hecho, entre las substancias materiales el género procede de la materialidad, mientras que en las substancias separadas debe tomarse de otra manera. Ahora bien, aparte de que esto es doctrina aristotélica, el hombre no es una substancia separada, sino una substancia que es corpórea y al mismo tiempo posee un ser capaz de subsistir sin cuerpo. Porque nuestra substancia es corpórea, pertenecemos a un género que compartimos con otros individuos de la misma especie y con individuos de otras especies. Del mismo modo, pertenecemos a una especie de la que hay otros individuos. Esto se puede verificar fácilmente en la experiencia, porque el objeto inmediato y natural del entendimiento humano es el ente sensible, compuesto, de tal manera que nuestro intelecto, que es simple, se conoce a sí mismo sólo por reflexión y por negación. De aquí que nuestro acto de intelección dependa de la fantasía y de los otros sentidos. Ese objeto y esa dependencia se da en todos los seres humanos que, por tanto, es claro que poseen un intelecto de la misma especie. El alma humana, además, por esa misma dependencia apuntada, no es una substancia completa, ni, por tanto, persona ${ }^{41}$. Sin embargo, podría concederse a Crosby que, puesto que nuestro ser es incorpóreo, aunque es verdad que, como se acaba de mostrar, poseemos un género y una especie común, somos una especie sui generis, que realmente participa del género común “animal” pero realmente lo trasciende ${ }^{42}$.

\footnotetext{
${ }^{40}$ Sobre Crosby, cfr., por ejemplo, "A Neglected Source of the Dignity of Persons" (cit.), p. 22. Sobre Seifert, cfr., por ejemplo, "Person und Individuum. Über Hans Urs von Balthasars Philosphie der Person in die philosophischen Implikationen seiner Dreifaltigkeitstheologie”. Forum katholische Theologie 13 (1997), pp. 81-105.

${ }^{41}$ Cfr. S. Th. I, q. 29, a. 1 , ad $5 \mathrm{~m}$.

42 Tal es también el fondo de verdad que puede reconocerse en la presentación que hace Josef Seifert de la definición clásica de hombre como animal racional, contenida en la primera sección de su conferencia "El hombre como persona en el cuerpo", cuyo texto amablemente me facilitó el autor (impartida en el Curso de Verano de la Universidad Complutense de Madrid, "El enigma del hombre”, organizado por la Asociación IUVE en julio de 1994). En esta pieza, Seifert, sin embargo, va demasiado lejos cuando critica la dicha definición. Afirma, en efecto, que es metafísicamente incorrecta y confusa porque en la definición del hombre, que constituye el horizonte entre lo sensible y lo espiritual, se pueden usar como géneros próximos o bien "animal" o bien "persona", pero debería "elegirse como fundamento [...] aquel género que es más importante para el ser correspondiente" y, por tanto, debió elegirse el género "persona” y no el género "animal” (o "viviente orgánico"). Según Seifert, si se elige como género "animal", entonces queda el elemento personal de la definición clásica, aludido en la partícula "racional", como algo sobreañadido a lo más fundamental, que sería el género. Digo que
} 
Un corolario de lo anterior sería que, aunque es verdad que no existe un género "substancia" común a las substancias corpóreas y a las substancias separadas, como muestra Aristóteles en el libro Iota (capítulo 10) de la Metafísica y como aguda e independientemente observa Josef Seifert ${ }^{43}$, no es verdad que "substancia" signifique algo enteramente distinto cuando se predica de lo corpóreo que cuando se predica de las personas. Seifert parece concebir al alma humana, y no tanto al hombre compuesto, como persona ${ }^{44}$. A esto añade que la persona es substancia porque posee su ser en la auto-conciencia, lo cual es un modo de auto-posesión de otro género respecto de aquél de la sustancia material ${ }^{45}$. Pero, aunque esto es parcialmente verdad, oculta un aspecto trascendental del tema. "Substancia" es lo que subsiste y no es en otro. En este sentido se dice como un cierto pròs hên, de modo semejante a ser. Se dice sobre todo de Dios y de modo menos perfecto de las substancias químicas y las partículas elementales, en cuanto a su significado más propio, aunque se diga primero de lo sensible en cuanto a su modo de significar. Hay, pues, una cierta comunidad de significado cuando se predica "substancia" de lo sensible y de las substancias separadas. En el caso de la persona humana se da ese significado, aun antes de que se dé la auto-posesión por la auto-conciencia $\operatorname{actual}^{46}$. Ésa es la razón por la que matar a un bebé no nacido es un homicidio, con independencia de si la ley humana lo castiga o no. De donde se ve que la noción de "substancia" que se dice de lo sensible no es del todo equívoca con la que se dice de la

Seifert va demasiado lejos porque, en realidad, lo más formal en una definición es la diferencia específica. Entonces, cuando se dice "animal racional" se está diciendo que "animal" queda informado e intrínsecamente modificado por "racional". En efecto, según Aristóteles y santo Tomás, lo que se pone como género se pone por razón de la materia. Con la definición clásica se deja claro, por tanto, que el hombre es básicamente racional y que la racionalidad forma una unidad substancial con la animalidad y, por tanto, con la corporalidad. En cambio, en la definición alternativa propuesta por Seifert, "persona que tiene un cuerpo" o "persona en el cuerpo", se encuentran dos graves problemas. El primero, que el género no ocupa el lugar material en la definición. El segundo, que la corporalidad queda como un añadido accidental de la personalidad, externa a ésta, de manera que esta definición, en realidad, no tiene género y diferencia, sino algo así como "esencia" y accidente.

${ }^{43}$ Cfr. Essere e Persona (cit.), pp. 339.

${ }^{44}$ Cfr. Essere e Persona (cit.), p. 340. Lo mismo ocurre a Crosby, aunque en menor grado. Cfr., por ejemplo, The Selfhood of the Human Person (cit.), pp. 138-139 y 143.

${ }^{45}$ Cfr. Essere e Persona (cit.), p. 344-347. Como vimos en las observaciones preliminares, Crosby es más cauto en este punto.

${ }^{46}$ Sorpresivamente, los canalsianos estarían de acuerdo con Seifert en este punto, pues sostienen que es inherente y esencial a la persona la auto-conciencia y que, en un sentido, el acto de entender se identifica con el acto de ser. Citan en su apoyo De Veritate q. 10, a. 8 (últimamente también citan Super De causis, l. XV). Pero ni en la persona angélica ni en la humana se da esa identidad. En el caso de la persona humana, existe un conocimiento habitual de sí que es innato, pero no un conocimiento actual. Ahora no puedo explicar en qué consiste dicho conocimiento. Debo apuntar, en cambio, que el intelecto humano que, como agudamente observa Aristóteles en el capítulo 6 del libro III del De Anima, sólo puede conocer en recto los todos compuestos, se eleva después a lo simple, pero por la vía de la negación. Por este motivo, el bebé que no ha alcanzado la primera captación intelectual del ser sensible no tiene conocimiento actual de sí mismo. Si no tuviera una substancialidad según el significado que tiene la palabra entre las substancias corpóreas, no sería, por tanto, persona. Pienso que es esto precisamente lo que mueve a Crosby a defender la definición boeciana de persona, si bien alterando su significado, como hemos visto. 
persona humana, pues también en el caso de la persona humana la esencia se da en un sujeto concreto y las apariencias pueden ocultar el verdadero ser. $\mathrm{Y}$ eso es así por lo que hemos dicho: la persona humana es realmente una substancia corpórea y, por eso, participa en el género de las substancias corpóreas. No somos ángeles.

De donde se sigue que la naturaleza humana es comunicable. Pero lo es no de una manera oculta, sino del modo abierto que encontramos en nuestra experiencia: el padre y la madre engendran a otro ser humano, son co-creadores. En esto, las ínfimas personas comunicamos de una manera maravillosamente alta en el Misterio de la vida íntima de Dios: el Padre engendra al Hijo y, por eso, de Aquél procede toda paternidad, en los cielos y en la tierra. Por esta comunicación del hombre con la Vida Trinitaria, pudo el Hijo, sea dicho de paso, tomar la naturaleza humana, pues "de cierto no tomó la semilla de los ángeles, sino la de Abraham" (Hebreos 2, 16).

Si se negara lo dicho, habría una grave dificultad para explicar cómo es que el género humano heredó el pecado original, cómo es que Cristo se hizo hombre, de tal manera que se constituyera una Persona (un Quién) con dos naturalezas ${ }^{47}$, o cómo es que el Sacrificio de la Cruz pudo expiar por los pecados de los hombres. No digo que los fenomenólogos realistas no podrían dar respuesta a estos problemas ${ }^{48}$, sino que sostengo que su respuesta tendría menos cohesión con su manera general de ver el mundo que la que tiene la formulación clásica de los misterios del pecado original y la redención. Para captar este punto, baste leer este pasaje: “[...] la humanidad de la persona forma tan estrecha unidad con su incomunicabilidad que la comunicabilidad propia de la humanidad se reduce y, según parece, queda casi abolida. [...] Nuestra pregunta puede formularse también así: ¿es suficiente decir que cada persona tiene algún contenido esencial como si él o ella fuera ese contenido [...], o tenemos que ir más lejos y decir que cada uno real y literalmente es ese contenido?"49. Por supuesto, cabe interpretar estas frases conforme a una formulación más feliz del propio Crosby, dada en el año 2004 ante una objeción teológica: "Podemos de hecho expresar la irrepetibilidad de las personas en términos que presuponen una naturaleza común, como cuando digo que cada persona humana tiene la naturaleza humana a su manera incomunicable e irrepetible. Este modo 'adverbial' de expresar la incomunicabilidad personal lo inserta desde el comienzo dentro de nuestra común naturaleza y evita aun la apariencia de anular esta naturaleza

${ }^{47}$ Cfr. S. Th. I q. 29, a. 1 , ad $2 \mathrm{~m}$.

48 De hecho, Crosby podría responder que la incomunicabilidad de la persona no excluye la comunidad o la solidaridad (The Selfhood of the Human Person [cit.], p. 58), pero encontraría dificultades para explicar esa comunidad en términos de naturaleza humana y en su conexión con la individualidad.

${ }^{49}$ Cfr. The Selfhood of the Human Person (cit.), pp. 63-64. 
común" ${ }^{50}$.

Debemos añadir que cuando se define al hombre como animal racional se encuentra el hablante en el plano esencial. Lo que se define así no es la persona, con su individualidad e incomunicabilidad, sino la esencia de la persona humana. Ahora bien, todos los individuos humanos son personas precisamente porque tienen esa esencia, porque son substancias primeras que subsisten en una naturaleza racional.

También respecto a la Trinidad surgen dificultades a partir de la noción fenomenológico-realista de persona, al menos a partir de la noción de John Crosby, pero me parece mejor no desarrollarlas ${ }^{51}$. Estoy seguro, en efecto, de que él podría aclarar los términos que ha usado y mostrar su compatibilidad con todos los aspectos de la formulación de este artículo de la Fe. Quizá estas páginas le den la ocasión propicia.

Universidade Católica de Petrópolis

Centro de Teologia e Humanidades

Rua Benjamin Constant, 213 - Centro - Petrópolis

Tel: (24) 2244-4000

synesis@ucp.br

http://seer.ucp.br/seer/index.php?journal=synesis

CASANOVA, Carlos. ¿HA SUPERADO LA NOCIÓN DE PERSONA QUE POSTULA LA FENOMENOLOGÍA REALISTA A LA NOCIÓN CLÁSICA, BOECIANA, DE PERSONA?. Synesis, http://seer.ucp.br/seer/index.php/synesis , v. 5, n. 2, p. 12-26, dec. 2013. ISSN 1984-6754. Disponível em: http://seer.ucp.br/seer/index.php?journal=synesis\&page $=$ articl e\&op=view\&path\%5B \%5D=431. Acesso em: 18 Dec. 2013.

50 "A Neglected Source of the Dignity of Persons" (cit.), p. 22.

${ }^{51}$ John Crosby señala a Dios como el caso supremo de incomunicabilidad, porque Él es su Divinidad sin que sea posible que haya otros dioses (cfr. The Selfhood of the Human Person [cit.], p. 45). Olvida en este pasaje el autor estadounidense que la Única Esencia Divina es comunicada por el Padre al Hijo y por Padre e Hijo al Espíritu Santo. Más adelante deja espacio Crosby para que las Tres Personas Divinas "compartan" la "naturaleza divina" (p. 58), pero quizá no subraya suficientemente que dicha Naturaleza es comunicada. El problema reaparece en la p. 64, donde dice Crosby que en toda persona debe haber un contenido esencial que no pueda ser participado por otra persona. -Y habla explícitamente de Dios... 